\title{
Some thoughts on the present and future of coronary artery stenting
}

Are you learning to interpret the new international language of stents? Are you still stuck with POBA (plain old balloon angioplasty) or are you "dog boning" your stent, avoiding "snowploughing" or "jailing" your diagonals, and leaving "hot" radioactive seeds behind to minimise restenosis? "T and A" no longer means "tonsils and adenoids" but ticlopidine and aspirin, and the main purpose of the cephalic vein is for coating stents rather than introducing permanent pacing electrodes. Clearly this is a good time to survey the stenting scene. The Second Thoraxcenter Course on Coronary Stenting provided a useful focus of stenting expertise and the views that follow are based on contributions that were made to discussions at the course.

The interaction between a biomechanical prosthesis and the arterial circulation is intriguing. Clinical techniques are being developed that reduce the risks of early subacute thrombosis and laboratory research is giving insights into the medium-term phenomenon of intimal hyperplasia. Nonetheless we must not lose sight of possible long-term adverse effects such as stent fracture or inflammatory reactions. Stent implantation developed from balloon angioplasty. ${ }^{12}$ Initially its role was to deal mechanically with acute vessel occlusion but the question that increasingly arises is: "should stenting be seen as a primary therapy?" As a solution to an engineering problem intracoronary stents seem a natural development but the biological consequences are obviouslychallenging. ${ }^{34}$

\section{Which stent should we choose?}

Currently six stents are commercially available. Each brings a different combination of characteristics that are claimed to help with implantation. At least ten other stents are in various phases of development.

- The stent needs to reach the lesion and remain there. Distal lesions and tortuous vessels require low profile and flexible stents.

- The stent needs to be deployed accurately. Stents made of radio-opaque material help with this: those

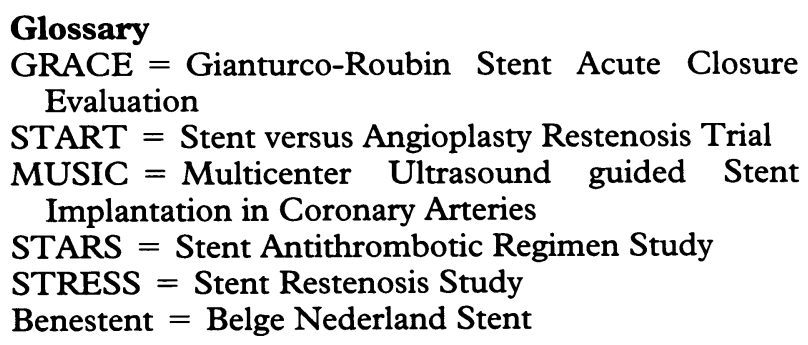

that are not, can be fitted with a marker at each end. Highly radio-opaque stents, however, can complicate angiographic assessment of stent deployment. This problem can of course be reduced by the use of intravascular ultrasound (IVUS).

- To ensure that the lesion is covered, stents should not shorten much when they are deployed.

- Many believe that the operator should aim to cover the entire length of the lesion with the stent. Unless intravascular ultrasound is used, it becomes a matter of judgement rather than measurement to determine where atheromatous plaque ends and the normal vessel begins. A larger range of lengths of stents will be available soon.

- Small diameter stents are necessary for lesions in small vessels and large diameter stents for vein grafts.

- There are two basic designs - coil stents and mesh stents. The mesh stent has better scaffolding properties and is quite stiff. The coil requires less metal, which might reduce the risk of acute thrombosis, and gives a greater degree of flexibility so that the stent follows the vessel curvature and makes it more suitable for lesions on bends.

- It is important that the stent does not become detached before it reaches its target. One way of preventing this problem is to cover the stent with a sheath. A reliable system of getting the premounted stent to adhere to the balloon delivery system is more likely to overcome the problem, however. This could be achieved by using a balloon with a rough surface.

- The operator needs to develop a cost effective strategy for each patient. Unfortunately there are insufficient clinical trials or even registries to allow the operator to make a well informed choice. It follows that familiarity with a restricted number of stents (for example, three) is the best current advice.

\section{Responsibilities shared by the interventionist and} manufacturers

Interventional cardiologists need to bear in mind that they are permanently implanting a foreign body. ${ }^{5} \mathrm{New}$ designs and new methods of manufacture should be thoroughly validated in animal models before they are introduced into clinical practice. Because they are disposable items of equipment, the development of PTCA balloons has been relatively rapid. In contrast, because stents are a long-term implant, registries will be required to validate the longterm safety of new products. Registries of devices may underestimate late complications. They are fundamentally much less satisfactory than randomised trials. But a properly set up and independently monitored registry is better than nothing. 
Ideally, data from randomised trials should be available before new stents are widely used. Such trials could involve a comparison of the new stent with either medical treatment or balloon angioplasty or even established stents. Inevitably such trials will be funded by the equipment manufacturers. For such trials to be valid they require an independent core laboratory, steering committee, and writing committee. The core laboratory would be responsible for recording clinical data and events data and angiographic assessment before and after the procedure. The core laboratory must be independent of the steering committee of the trial and together with the writing committee must be independent of the source of funding. Although a direct analogy with mechanical valve prostheses or atrial pacing wires is inaccurate we would be wise to be aware of previous adverse effects associated with permanent endovascular implants. It follows that we should support the idea of a standardised testing procedure for any suggested new intracoronary implant. If the profession does not adequately address these issues then governments may impose regulations which will restrict our freedom to develop new techniques in interventional cardiology.

\section{Anticoagulation and stents}

Laboratory investigations suggest that the expression of fibrinogen and P-selectin receptors on the surface of activated platelets may be an important risk factor for subacute stent thrombosis. It is therefore not surprising that there is increasing clinical evidence that a combination of antiplatelet drugs such as ticlopidine and aspirin is better than warfarin for "anticoagulation" after stent implantation. ${ }^{6}$ Not only is there a decreased risk of haemorrhage at the access site, but in addition the mechanism of action of the combination of ticlopidine and aspirin may be a more powerful means of reducing aggregation of platelets. Dr Schömig suggested that warfarin might even be harmful when stents are used to treat acute myocardial infarction.

An alternative approach focuses on the IIb/IIIa receptor site which becomes exposed when platelets are activated. Systemic administration of $\mathrm{Ilb} / \mathrm{IIIa}$ inhibitors at stent implantation is likely to prove effective in reducing subacute stent thrombosis, but could increase bleeding at the vascular access site. Another approach to make stents non-thrombogenic would be to include such drugs in the coating of the stent. Preliminary experimental and clinical evidence shows a reduction in thrombosis associated with heparin coated stents. ${ }^{7}$ However, the issue of an inflammatory response of the vessel wall to the polymer coating requires further careful study.

\section{Cost effectiveness}

The cost effectiveness of intracoronary stenting will undoubtedly continue to exercise the minds of purchasers of health care. The overall health care costs associated with coronary stenting are falling rather than rising. This is because current methods of anticoagulation no longer include warfarin. This substantially reduces the cost associated with the length of stay in hospital. Potentially some of these benefits could be lost if the need for high pressure balloon inflations were to lead to an increase in the number of balloons used per procedure. Fortunately a reduction in costly adverse late cardiac events was seen in the Benestent-I and STRESS studies. ${ }^{89}$

Dr David Cohen (Harvard School of Public Health) looked at the effect of changes in clinical practice on the relative costs of stenting and PTCA. It looks as if stenting is becoming more cost effective although it still remains marginally more expensive than ordinary angioplasty. ${ }^{10}$ The substantial potential cost saving of the radial approach was emphasised by Dr F Kiemeneij, (Onze Lieve Vrouwe Gasthuis, Amsterdam). The possibility of performing up to $60 \%$ of stent implantations as an outpatient procedure has obvious economic attractions. To control costs we must aim for the ideal of one stent and one balloon for optimal delivery of a coronary stent.

\section{The trials}

Two randomised trials (GRACE and Stent-by) have compared stents with perfusion catheter as a bail-out device for threatened or acute vessel closure. Particularly striking is the subgroup of patients who crossed over from perfusion balloon to stenting who had a better outcome than those who were treated by perfusion balloon alone. It seems likely that stents will now replace perfusion balloons as the preferred treatment for acute vessel closure.

A meta-analysis of Benestent-I and STRESS I and II showed that in general, stents give better clinical results at six months than simple angioplasty. Clinically it seems that the increased intimal hyperplasia associated with stents is more than offset by the reduction in vessel recoil seen after angioplasty. These results are also confirmed by the Spanish START trial. The design of these trials included warfarin and therefore it is not surprising to find an increased incidence of complications associated with vascular access in the stent group.

Currently the most important clinical question is whether, with the current strategy of ticlopidine, aspirin, and high pressure inflation, routine intravascular ultrasound is needed or cost effective to assess the quality of the stent implantation. Incomplete expansion, incomplete apposition of the stent to the vessel wall, and local tears may not be detected by angiography. Although with an apparently "good" angiographic result IVUS may show that further improvement in the result may be possible. ${ }^{11}$ The MUSIC and STARS trials have been designed to determine whether further IVUS guided intervention after high pressure inflation will improve clinical outcome. We should know the result of the MUSIC study soon.

\section{The future}

\section{DRUG DELIVERY SYSTEMS}

Polymers rather than metals could be used as the chief constituent of stents. This might facilitate local drug delivery but could lead to an inflammatory response. The excellent current results of clinical trials suggest that stents may not need local drug delivery systems. But these were trials in patients with stent favourable lesions $(<15 \mathrm{~mm}$ long) in large vessels ( $>3 \mathrm{~mm}$ in diameter) and most patients seen in routine clinical practice have lesion characteristics that are not stent favourable (long or thrombotic lesions, small vessels). Such patients are likely to benefit from effective local drug delivery.

The clinically apparent biological adverse processes associated with stent implantation are subacute stent thrombosis and intimal proliferation. Intimal proliferation is more likely to be of long-term clinical importance and the incidence of stent thrombosis seems to be declining.

Subacute occlusion could be further reduced by local drug delivery using binding or eluting with agents such as IIb/IIIa inhibitors or nitric oxide. Heparin and steroids have also been investigated. Successful progress in pharmacological prevention of subacute occlusion should minimise the use of multiple balloons or IVUS-thus containing costs. Lesions presenting as unstable angina or acute infarction might benefit from pharmacological "pas- 
sivation". A component of intimal proliferation may be initiated by the acute platelet mediated thrombus so effective local antithrombotic drug treatment may reduce restenosis.

\section{Radiation}

A promising new method of controlling smooth muscle cell proliferation is radiation. ${ }^{12}{ }^{13}$ In animal models incorporation of gamma radiation sources into the stent structure is associated with a striking reduction in smooth muscle cell proliferation. ${ }^{12}$ Fortunately, the endothelial cells are much less sensitive to radiation and an intact layer of endothelium covers the stent material and reduces the risk of subacute occlusion. The inhibitory effect of gamma radiation on smooth muscle cell proliferation follows a dose response curve and apparently low and safe radiation doses reduced the size of the neointima at both 4 and 52 weeks. The cellular component of the neointima was greatly reduced and consisted largely of fibrous tissue.

Phosphorus-32 is a possible therapeutic radioactive agent. It is a beta-emitter with a short half life and virtually no residual activity four weeks after implantation. Little radiation is delivered outside the artery.

Dr $\mathbf{P}$ Teirstein (Scripps Clinic and Research Foundation, La Jolla, California) described interesting preliminary clinical work in patients presenting with restenosis. With the assistance of a radiation oncologist he has left a ribbon of iridium within the lumen of the stent for up to 30 minutes. The clinical results of this treatment in a high risk group of patients who had already had one episodes of restenosis are awaited with interest.

There was also much interest in the concept of covering a stent with a portion of vein. A cephalic vein seems to be the most suitable source. Dr I Stefanides (Social Security Foundation, Athens) described how the vein can be inserted into a slightly distended stent, the vein folded over the outside of the stent sutured together and the stent then crimped onto a balloon ready for delivery. This arrangement prevents the metal component of the stent coming in direct contact with the circulating blood. Others have attached vein to the outside of the stent to prevent neointimal hyperplasia within. Once again, the potential clinical benefit of these innovations will require careful clinical trials.

\section{Unresolved issues}

It seems that 1995 was the stent "breakthrough" year. Much has been learned but many issues remain unresolved-such as:

- What is the place of ultrasound in optimising stent deployment?

- What will be the immediate and long-term outcomes of stenting in smaller vessels, longer lesions, unstable lesions, acute infarct lesions, venous bypass lesions?

- To what extent does stenting preventing restenosis and how should we treat restenosis in a stent?

PIM J DE FEYTER

International Advisory Board, Heart PETER N RUYGROK

Green Lane Hospital, Auckland, New Zealand PETER MILLS

Associate Editor, Heart

We thank Claudia Sprenger de Rover for her invaluable assistance with this paper.

1 Gruentzig AR, Senning A, Siegenthaler WE. Non-operative dilatation of coronary artery stenosis: percutaneous transluminal coronary angioplasty. N Engl ₹ Med 1979;301:61-8.

2 Sigwart U, Puel J, Mirkovitch V, Joffre F, Kappenberger L. Intravascular stents to prevent occlusion and restenosis after transluminal angioplasty. $N$ Engl f Med 1987;316:701-6.

3 Schatz R. A view of vascular stents. Circulation 1989;79:445-57.

4 Leon MB, Wong SC. Intracoronary stents: a break through technology or just another small step? Circulation 1994;89:1323-7.

5 Topol EJ. Caveats about elective stenting. $N$ Engl $\mathcal{G}$ Med 1994;331:539-41. Morice MC, Zemaur G, Benvishe E, Biron Y, Bourdonnec C, Faivre R, et al. Intracoronary stenting without coumadin: one month results of a French multicenter study. Cathet Cardiovasc Diag 1995;35:1-7.

7 Serruys PW, Emanuelsson H, van der Giessen W, Lunn A, Kiemeneij F, Macaya C. Heparin coated stents in human coronary arteries: early outcome of Benestent II pilot study. Circulation 1996;93:412-22.

8 Serruys PW, de Jaegere P, Kiemeneij F, Macaya C, Rutsch W, Heyndrickx $\mathrm{G}$, et al. A comparison of balloon-expandable stent implantation with balloon angioplasty in patients with coronary artery disease. $N$ Engl $f$ Med 1994;331:489-95.

9 Fischman DL, Leon M, Baim DS, Schatz RA, Savage MP, Penn I, et al. A randomized comparison of coronary stent placement and balloon angioplasty in the treatment of coronary artery disease. $N$ Engl $f$ Med 1994;331:496-501.

10 Cohen DJ, Breall JA, Ho KKL, Kuntz RE, Goldman L, Baim DS, et al. Evaluating the potential cost-effectiveness of stenting as a treatment for symptomatic single-vessel coronary disease: use of a decision analytic model. Circulation 1994;89:1859-74.

11 Colombo A, Hall P, Nakamura S, Almagor Y, Maiello L, Martini G, et al. Intracoronary stenting without anticoagulation achieved with intravascuIar ultrasound guidance. Circulation 1995;91:1676-88.

12 Hehrlein C, Gollan C, Dönges K, Metz J, Riessen R, Fehsenfeld P, et al. Low-dose radioactive endovascular stents prevent smooth muscle cell Low-dose radioactive endovascular stents prevent smooth muscle cell
proliferation and neointimal hyperplasia in rabbits. Circulation 1995;92: prolifera

13 Waksman R, Robinson KA, Crocker IR, Gravanis MB, Palmer SJ, Wang $\mathrm{C}$, et al. Intracoronary radiation before stent implantation inhibits neoinima formation in stented porcine coronary arteries. Circulation 1995; 92:1383-6. 